УДК

\title{
О МИНИАТЮРИЗАЦИИ ЭФФЕКТИВНОЙ СВЕРХШИРОКОПОЛОСНОЙ ПЕЧАТНОЙ АНТЕННОЙ РЕШЕТКИ КВАЗИ-ЯГИ
}

\author{
А. ХАРМОУЧ ${ }^{*}$, В. ХАРМОУЧ ${ }^{1}$, А. АХМАД ${ }^{2}$, М. КЕНААН ${ }^{3}$, Ж.-М. ФЛОР \\ ${ }^{1}$ Ливанский университет, \\ Ливан, Триполи \\ ${ }^{2}$ Университет искусств, науки и техники, \\ Ливан, Триполи \\ ${ }^{3}$ Университет Аль Кафаат, \\ Ливан, Бейрут \\ ${ }^{4}$ Реннский институт электроники и телекоммуникаций, \\ Франциия, Рен
}

\begin{abstract}
Аннотация. В статье представлены конструкция и анализ компактной эффективной сверхширокополосной однонаправленной печатной антенной решетки для применений внутри помещений. Антенная решетка размерами $12,2 \times 6,3 \times 1$ см перекрывает сверхширокий диапазон частот от LTE до Wi-MAX со средним коэффициентом усиления 5 дБ во всем диапазоне частот. По сравнению с существующими антенными системами предложенная антенна имеет значительно лучшие технические характеристики и большую компактность, что делает ее конкурентоспособной по сравнению с другими моделями антенн. Результаты моделирования показывают низкие уровни кросс-поляризации, где уровень боковых лепестков также минимизируется путем введения в проектируемую модель специального отражающего элемента. Использование предлагаемой антенны в системах связи внутри помещений позволяет повысить качество сигнала в пределах зоны покрытия и минимизирует количество точек доступа, необходимых для данной сети.
\end{abstract}

Ключевые слова: компактный; сверхширокополосный; однонаправленный; связь внутри помещений; полоса пропускания; диапазон частот; коэффициент усиления; уровень боковых лепестков; антенная решетка

\section{1. ВВЕДЕНИЕ}

За последние годы распространение систем мобильной связи заметно выросло, и рыночный спрос на подобные системы продолжает расти. Антенна, как главная часть этих систем, представляет собой одну из наиболее важных конструктивных элементов при разработке современных устройств мобильной связи. В силу того, что антенны являются частотно-зависимыми, они конструируются для работы в определенных частотных диапазонах.

DOI: $10.20535 / \mathrm{S} 0021347017060024$

(C) А. Хармоуч, В. Хармоуч, А. Ахмад, М. Кенаан, Ж.-М. Флор, 2017
Из-за быстрого роста числа систем мобильной связи, упор сделан на использовании новых антенных систем для применения на базовых станциях и в мобильных устройствах (мобильный телефон, ноутбук, личный электронный секретарь (PDA), IP-маршрутизатор и т.п.). В 1990-х годах мобильные системы разрабатывались для работы в одном из диапазонов систем второго поколения (2G), например системы цифровой сотовой связи (стандарт DCS), служба персональной связи (концепция PCS) и глобальные системы мобильной связи (стандарт GSM). Однако в настоящее время 


\section{БИБЛИОГРАФИЧЕСКИЙ СПИСОК}

1. Saunders, Simon R. Antennas and Propagation for Wireless Communication Systems. — England : Wiley, 1999.

2. Balanis, C. A. Antenna Theory: Analysis and Design. - 3rd ed. - New Jersey : John Wiley \& Sons, Inc., 2005 .

3. Elsherbeni, A. Z.; Eldek, A. A.; Smith, C. E. Wideband slot and printed antennas. Encyclopedia of $R F$ and Microwave Engineering : ed. by K. Change. - John Wiley, Jan. 2005.
4. Qian, Y.; Deal, W. R.; Kaneda, N.; Itoh, T. Microstrip-fed quasi-Yagi antenna with broadband characteristics. Electron. Lett. - 1998. - Vol. 34, No. 23. — P. 2194-2196. — DOI : 10.1049/el:19981583.

5. Eldek, A. A.; Elsherbeni, A. Z.; Smith, C. E. Wideband microstrip-fed printed bow-tie antenna for phased-array systems. Microwave Opt. Tech. Lett. - Oct. 2004. - Vol. 43, No. 2. - P. 123-126. - DOI : 10.1002/ mop.20396.

6. Floc'h, J. M.; Ahmad, A. El Sayed. Broadband quasi-Yagi antenna for $\mathrm{WiFi}$ and WiMax applications. Wireless Engineering and Technology. - 2013. _ Vol. 4, No. 2. - P. 87-91. - DOI : 10.4236/wet.2013.42013.

7. Harrington, R. F. Effect of antenna size on gain, bandwidth, and efficiency. J. Research of the National Bureau Standards. Section D: Radio Propagation. Jan.-Feb. 1960. - Vol. 64-D, No. 1. — P. 1-12. — DOI : 10.6028/jres.064D.003.

8. Chu, L. J. Physical limitations of omni-directional antennas. J. Appl. Phys. - Dec. 1948. - Vol. 19, No. 12. — P. 1163-1175. - DOI : 10.1063/1.1715038.

9. Wheeler, H. A. Fundamental limitations of small antennas. Proc. IRE. — Dec. 1947. - Vol. 35, No. 12. P. 1479-1484. — DOI : 10.1109/JRPROC.1947.226199. 